\title{
Characteristics of Household Air Blast Freezing Design for Marine Products
}

\author{
Darwin R.B Syaka ${ }^{1}$, Ragil Sukarwo ${ }^{2}$, Ahmad Azhar ${ }^{3}$ \\ \{drbsyaka@unj.ac.id $\left.{ }^{1}\right\}$ \\ Department Mechanical and Vocational Education, State Universityof Jakarta, Gedung B \\ KampusRawamangun Jl. Rawamangun Muka Jakarta, Indonesia, $13220^{123}$
}

\begin{abstract}
The major problem of archipelago communities is the storage of seafood that depends on a particular season. In order for seafood to be preserved for long periods of time then, it should be frozen using air blast freezing. However, the existing air blast freezing is still on an industrial scale. Therefore, the aim of this study is to design the air blast freezing prototype of household scale to preserved seafood as a means of improving the economic resilience of archipelago communities. This research is preceded by design for refrigeration system followed by testing to obtain operational parameters which then will be validation and analysis of refrigeration system. The results of this research are design, operational and analysis methods to determine parameters and specifications of air blast freezing components including: pressure of system, cooling temperature, compressor power required, cooling load and evaluation required for his performance to be better.
\end{abstract}

Keywords: archipelago, seafood, preserved, air blast freezing, household scale.

\section{Introduction}

To improve the economy of the archipelago communities has various problems, such as: capital, unstable productivity, and various other things. And the most specific thing that usually becomes the main problem is the storage of marine products that are still dependent on those that exist in certain seasons. The main results of the archipelago communities are generally fish-based, which is known, that the fish is easily damaged (rot), and only able to survive about 8 hours after the arrest. The causes of fish quickly decompose, among others, due to microorganisms, such as bacteria and fungi [1].Commonly used storage / preservation methods are basically divided into 4 groups, ie 1) using physical factors, 2) preservatives, 3) utilizing physical factors and preservatives, and 4) fermentation. But for further processing, fish preservation should be done without changing the texture / shape, taste, and smell of fish. So the best process is to take advantage of physical factors, and physical factors that mean using low temperatures because the advantage of using low temperatures will make the material in durable does not change the texture / shape, taste, and smell [1].

Commonly used low temperature preservation methods are freezing, air blast freezing or cryogenic. Comparative study of the 3 methods was performed by M. Bueno, et al. [2]states that after being stored for 10 months, the method of air blast freezing has the quality of the meat closest to fresh meat. Similar research conducted by E. Muela, et al. [3] also supports the result that the method of preservation with air blast freezing at the final temperature of pruduk

ICCSET 2018, October 25-26, Kudus, Indonesia

Copyright (C) 2018 EAI

DOI 10.4108/eai.24-10-2018.2280639 
$-18^{\circ} \mathrm{C}$ has the meat quality closest to fresh meat after being stored for 1,3 and 6 months. This occurs because the method of fast freezing (blast freezing) offers a new technique for disrupting microbial cells [4] and with this method the recovery is relatively higher than that obtained by other methods[5]. As for the marine products should be cooled to the final temperature of $-15^{\circ} \mathrm{C}[6]$. Although the results of the preservation study on the fillet quality of catfish species with cryogenic method were better than the air blast freezing method but the quality did not differ significantly [7] but, compared with the 3 preservation methods at other low temperatures, cryogenic method the highest investment and operational costs [8], therefore the method of air blast freezing is a preferred method of preserving marine products suitable for archipelago communities.

Air blast freezing is a cooling technique by utilizing air to keep the temperature inside the cabin so that the inside temperature of the cabin remains stable and there is no temperature rise in the cabin [9]. Air blast freezing has flexibility because the air on the fan can overcome various forms of irregular product and various sizes besides that exhaled air causes uniform temperature in the cabin room so that cooling can take place evenly. Freezing with air blast freezing depends on the air velocity and the preparation of the rack so that circulation can be well circulated then the temperature will quickly cool to produce the optimum temperature for cooling the product. The advantages of the air blast freezing method are the flexibility and low capital cost [10] however, the existing blast freezer water cooler in the market is now still in industrial scale, making it expensive and large in size, therefore air blast freezing is not suitable for remote archipelago communities that has not too much production.

The capacity of air blast freezing suitable for archipelago communities is on the household scale. When designing and creating a home-scale air blast freezer is required caution, since failure in design will result in uneven product freezing [10]. Studies related to the design of today's air blast freezing focus on the cooling air distribution characteristics. Study of cold air distribution characteristics performed by Justo et al. [11], stating that using a computional fluid dynamic (CFD) simulation can improve cooling room design for better cold air distribution optimize fan power so as to reduce total energy consumption by $12 \%$. A special study of the characteristic design of cooling air distribution in the freezing process of fish products with industrial air blast freezing has been carried out by Walnuma et al. [12], using Modelica simulations suggests that in general this model can be a useful tool for visualization of austerity measures energy. However, the study of the simulation model of cold air distribution in the household scale and the validation of the model by testing has not yet been met. In addition, studies that validate the appropriateness of design parameters with operational parameters for economical, efficient and environmentally friendly refrigeration systems in household scale are also not yet met.Based on the above, it is proposed the research will concentrate on the study of the design model of the air blast freezing refrigeration system in the household scale and validate the model by testing. The main target of this research is to look for design parameters and operation of household air blast freezing in order to improve the economic resilience of archipelago communities. 


\section{Method}

This research is preceded by design for refrigeration system followed by testing to obtain operational parameters which further validation and analysis of the design and operational parameters of this air blast freezer refrigeration system. The design of the refrigeration system aims to obtain the appropriate temperature and pressure. This simulation design uses CoolPack software to determine the expected temperature, pressure and refrigeration capacity. Furthermore, the results of data analysis of temperature and pressure and refrigeration capacity obtained from CoolPack used as input data to calculate the length of capillary pipe by using DanCap software. The test equipment used is 735 Wattcondensing unit using refrigerant R-22 for air conditioning application. Freezer box as a cooling chamber or cabin has a volume 142 L. The test equipment can be seen in Figure 1.

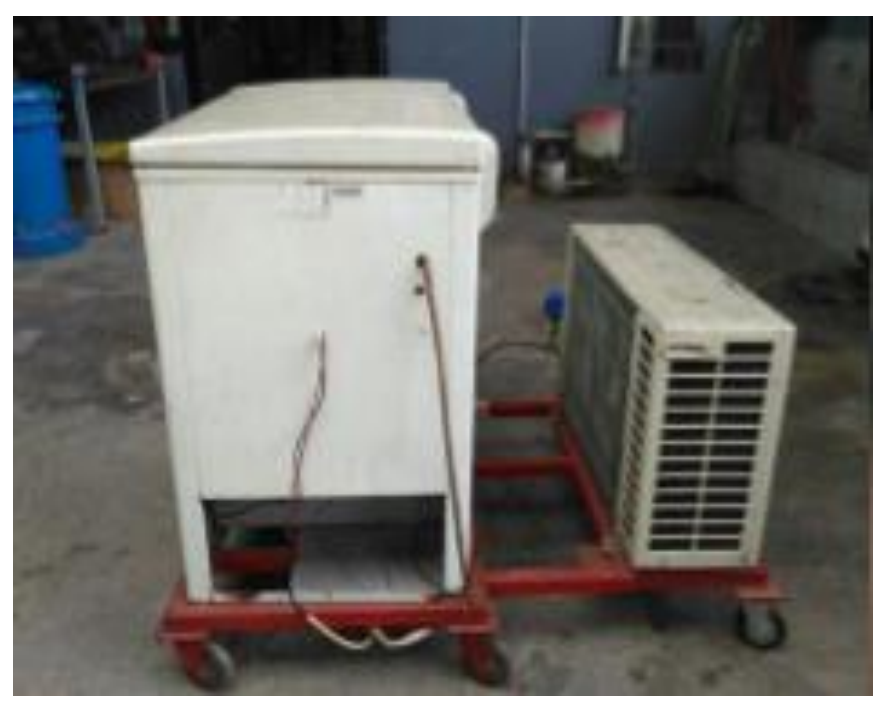

Fig. 1. The test equipment.

Data collection is done by measuring the exit temperature of the compressor, condenser, expansion valve and evaporator, as well as pressure in high pressure pipe and low-pressure pipe before and after compressor. Temperature measurements are carried out with a digital thermometer. Pressure measurements are made with analog pressure gauge. The voltage and current measurements required by the compressor are used to calculate the power absorbed by the compressor. Data retrieval is carried out until a steady state system which takes about 180 minutes, which data retrieval taken every 5 minutes.Furthermore, based on the data test are simulated with the help of CycleTempo software to validate and analyze the parameters of design and operational desired, so it can be known shortcomings that occur in order to further be used as a reference to improve the performance of this air blast freezing. 


\section{Result and Discussion}

\subsection{Design}

Design parameters of the air blast freezing household scale expected has temperatures below $20^{\circ} \mathrm{C}$ without the formation of frosting, with cooling time of less than 8 hours for marine products to be more durable with cooling at low temperatures in order to microorganisms in marine products not to thrive. Therefore, designed this refrigeration system has temperature evaporator $-30^{\circ} \mathrm{C}$ and temperature-superheating temperature taken $-5^{\circ} \mathrm{C}$. However, the freezers in the market today generally only reach temperatures of -2 to $8^{\circ} \mathrm{C}$ because they still use R$134 \mathrm{a}$, so the solution to achieve below $-20^{\circ} \mathrm{C}$ is to use refrigerant has lower normal boiling point, up to $-40^{\circ} \mathrm{Ci}$.e. R- 22 . In designing the condenser is cooled by air using the average temperature of outside air in Indonesia based on SNI standard that is $\pm 35^{\circ} \mathrm{C}$ and taken temperature sub cooling $30^{\circ} \mathrm{C}$. CoolPack software is used to obtain state points as shown in Figure 2.

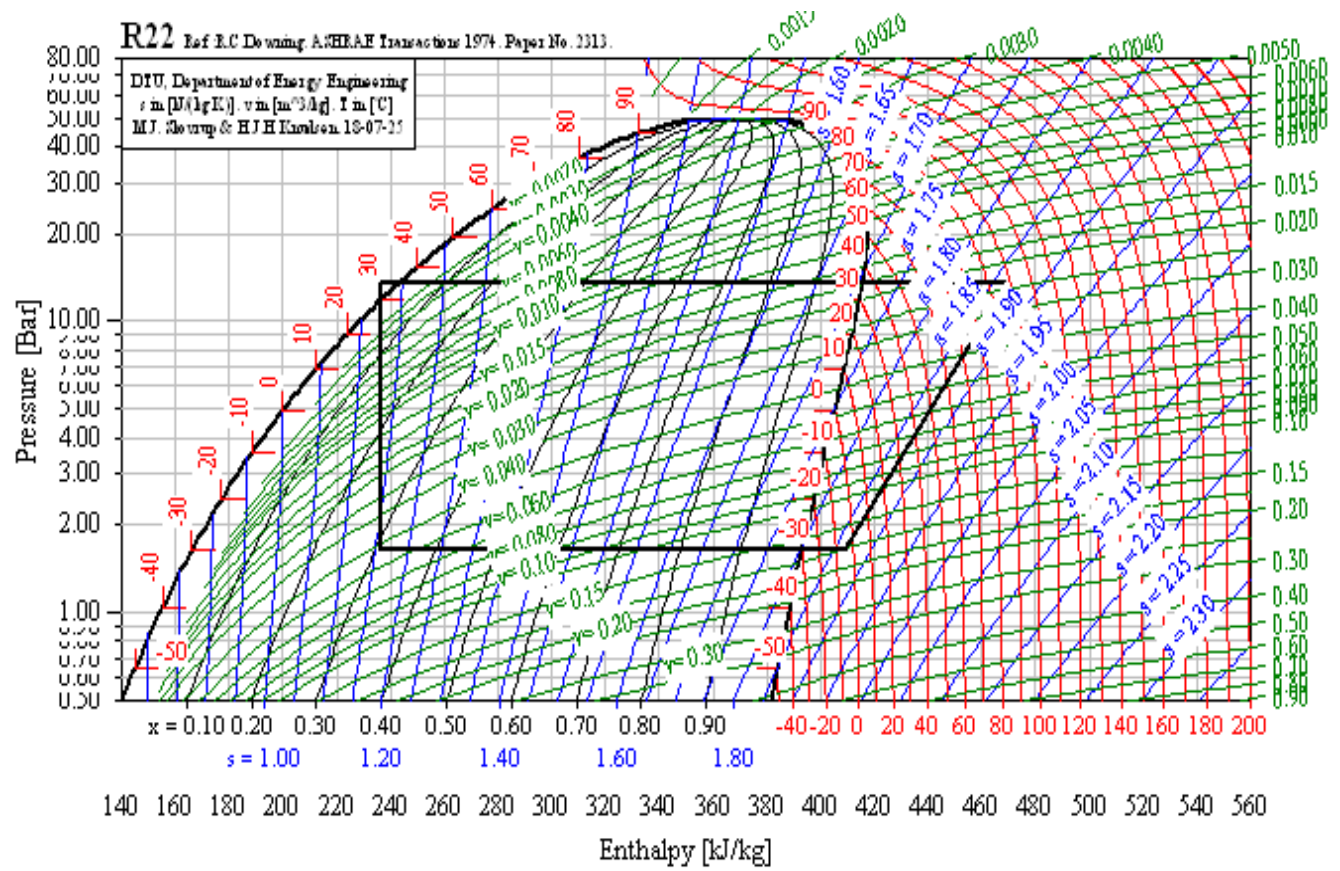

Fig. 2. State point of refrigeration cycle design.

With respect to the condensing unit specification used with $0.735 \mathrm{~kW}$ powered compressor, using DanCap software, the capillary length will be used in 0.035 inch diameter and $65 \mathrm{~cm}$ length. 


\subsection{Experiment}

According of the design point state then, the evaporator pressure is set at $\pm 1.7 \mathrm{bar}$, this results in a condenser pressure of \pm 11 bar, as shown in Figure 3. Evaporating pressure after the start of refrigeration system is relatively stable until 180 minutes. Furthermore, decreases with the decreasing evaporator temperature however the compression ratio that occurs almost always constant that is about 6.33. This higher compression ratio causes the compressor to work harder so that the power absorbed by the compressor is $0.77 \mathrm{~kW}$ higher than the compressor specification used is $0.735 \mathrm{~kW}$.

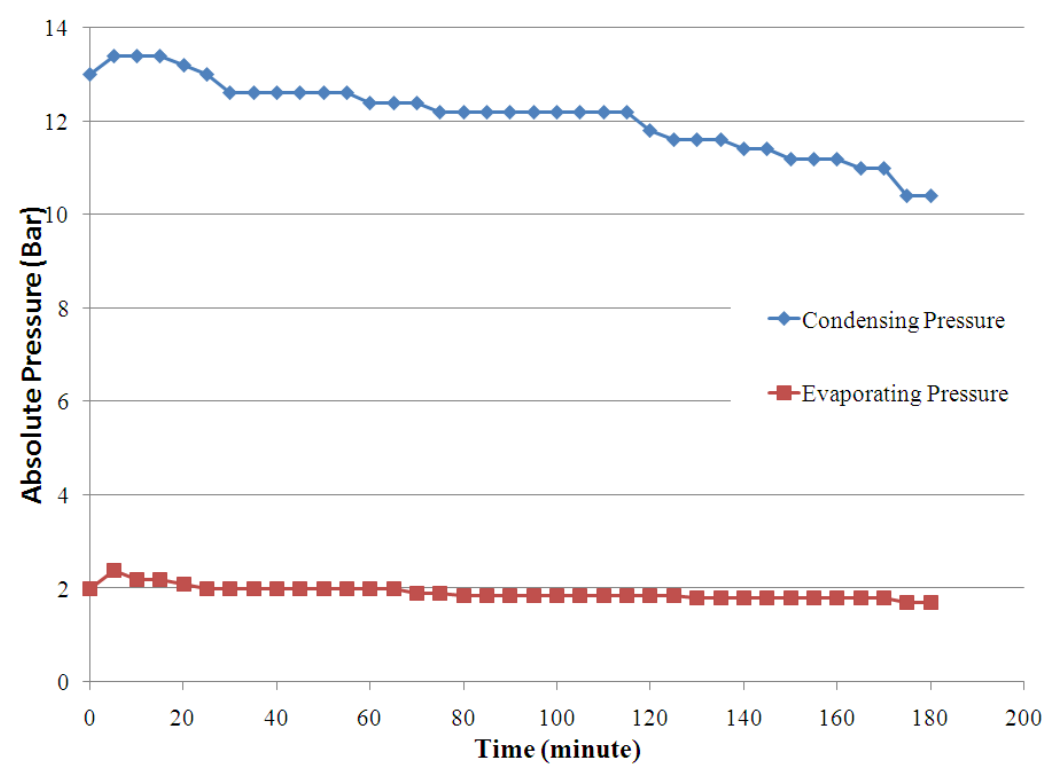

Fig. 3. Pressure of refrigeration system.

The higher compression ratio also causes the temperature of the refrigerant entering the condenser to be higher that is above $100^{\circ} \mathrm{C}$, however the condenser capacity used is still able to dissipate heat and condense the refrigerant in the system, it is marked by constant temperature refrigerant out of the condenser although the refrigerant temperatures enter the higher condenser as shown in Figure 4. 


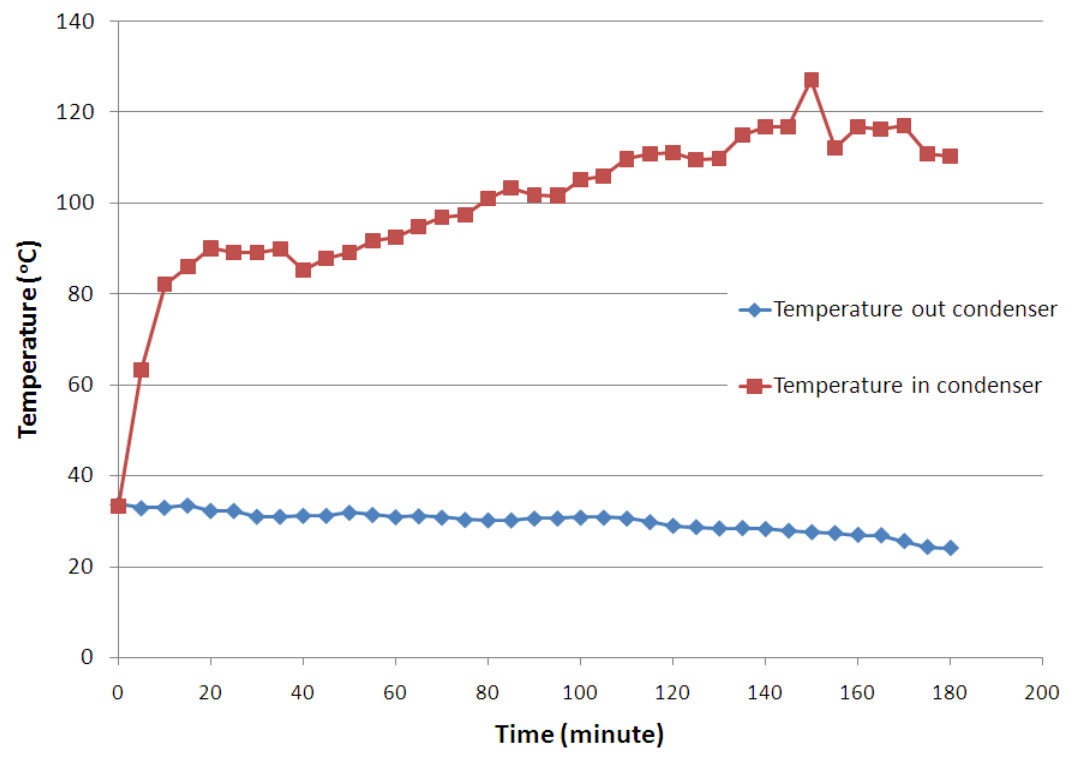

Fig. 4. Temperatures of condenser.

Figure 5 shows the temperature of the evaporator and the temperature of the cooling chamber (cabin) as time increases. Significant decrease in temperature at 60 minutes after start of refrigeration system and at the last 60 minutes temperature testing began to stabilize. In Fig. 5 it shows that there is a temperature difference $\pm 10^{\circ} \mathrm{C}$ between evaporator and cabin, this indicates that the evaporator used is less able to absorb heat from the cabin effectively.

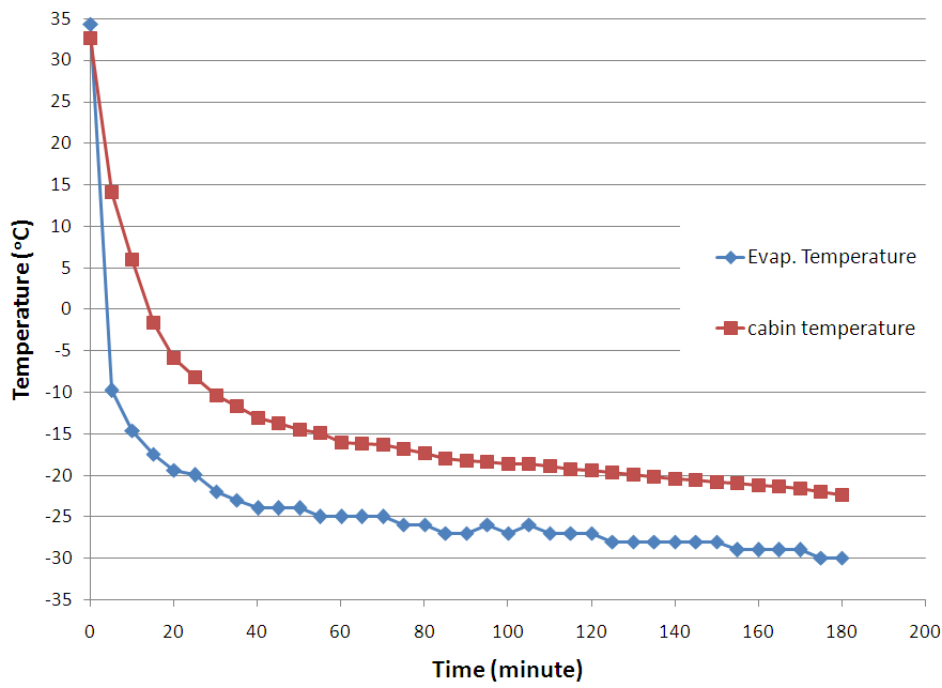

Fig. 5. Temperature of evaporator and cooling chamber (cabin). 


\subsection{Analyze and Evaluation}

Based on the results of subsequent experiments the evaluation was performed using the help of the CycleTempo software, which results as shown in Fig. 6. When compressor absorbing power of $0.77 \mathrm{~kW}, 0.008 \mathrm{~kg} / \mathrm{s}$ refrigerant flow in the refrigeration system and isentropic efficiency that occurs is $92.2 \%$ while the $1.8 \mathrm{~kW}$ heat out from condenser while the steam quality out of the expansion valve is $31.21 \%$.

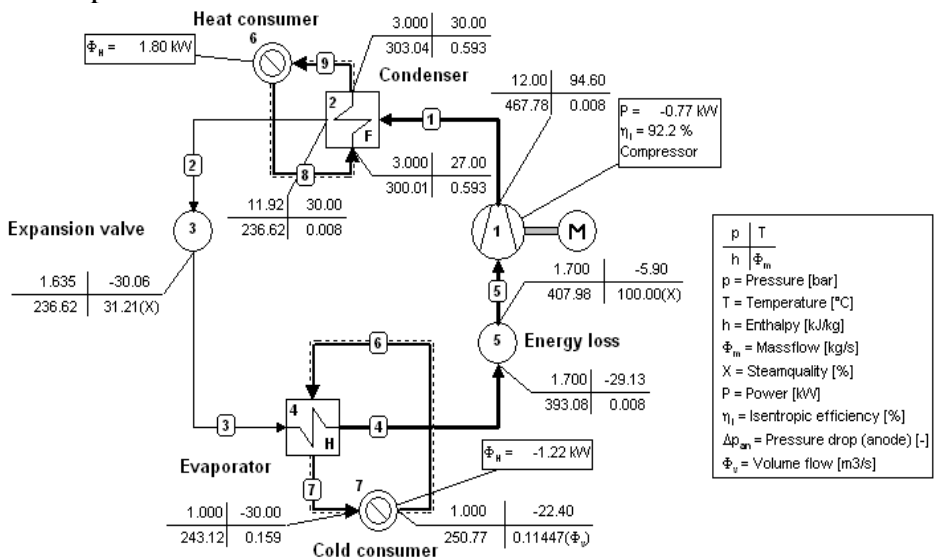

Fig. 6. Experimental evaluation using CycleTempo software.

The heat that can be absorbed by the evaporator in this system is $1.22 \mathrm{~kW}$ where its airflow rate is $0.11447 \mathrm{~m}^{3} / \mathrm{s}$, corresponding to the evaporator outlet area of $0.0432 \mathrm{~m}^{2}$ then the airflow velocity occurring in the evaporator is only $2.65 \mathrm{~m} / \mathrm{s}$. this means still below the required airflow velocity for air blast freezing of at around $4 \mathrm{~m} / \mathrm{s}$ [10]. This is what makes the temperature difference between evaporator and air-cooling room still big enough (fig. 5). Based on the analysis in Fig. 6 also the Coefficient of Performance (COP) is relatively low, that is 1.58 . Therefore, it should be considered to use a two-stage cascade refrigeration system to reduce the compressor compression ratio so that the compressor work becomes lighter.

\section{Conclusions}

According to the results of this research, some conclusions can be drawn as follows:

1) The design of air blast freezer refrigeration system using R-22 for household scale can be aided by using CoolPack and DanCap software.

2) The experiments were obtained by temperature at evaporator $-30^{\circ} \mathrm{C}$ and cabin/cooling chamber $-22.4^{\circ} \mathrm{C}$ at 1.7 bar evaporating pressure with compression ratio \pm 10 .

3) Based on the experimental evaluation analysis it is found that there is still a shortage of airflow velocity in the evaporator and for better system performance it is necessary to consider using two-stage cascade refrigeration system. 


\section{Acknowledgments}

This research was support by Hibah Penelitian Dasar Unggulan Perguruan Tinggi Tahun Anggaran 2018, Director General of Higher Education, Minister of Research, Technology and Higher Education.

\section{References}

[1] R. Adawiyah, Pengolahan dan Pengawetan Ikan, Ed. 1, Cet. Jakarta: Bumi Aksara, 2011

[2] M. Bueno, V. C. Resconi, M. M. Campo, J. Cacho, V. Ferreira, and A. Escudero, "Effect of freezing method and frozen storage duration on odor-active compounds and sensory perception of lamb," Food Res. Int., vol. 54, no. 1, pp. 772-780, 2013.

[3] E. Muela, C. Sañudo, M. M. Campo, I. Medel, and J. A. Beltrán, "Effect of freezing method and frozen storage duration on lamb sensory quality," Meat Sci., vol. 90, no. 1, pp. 209-215, 2012.

[4] A. Tanaka, "A Novel Method a 'Freeze-Blast' Method Disrupt Microbial Cells to," vol. 67, no. 1, pp. 52-56, 1989.

[5] A. T. Yoshiyuki Omori, Masanori Tsumura, Taizo Ichida, Hiroki Nakajima, Mitsuyoshi Ueda, Fumihiko Sato, Yasuyuki Yamada, "Application of the Freeze-Blast Method to Disruption of Cultured Plant Cells," J. Ferment. Bioeng., vol. 69, no. 2, pp. 132-134, 1990.

[6] J. B. Dima, M. V. Santos, P. J. Baron, A. Califano, and N. E. Zaritzky, "Experimental study and numerical modeling of the freezing process of marine products," Food Bioprod. Process., vol. 92, no. 1, pp. 54-66, 2014.

[7] L. A. Espinoza Rodezno et al., "Cryogenic and air blast freezing techniques and their effect on the quality of catfish fillets," LWT - Food Sci. Technol., 2013.

[8] J. M. Chourot, H. Macchi, L. Fournaison, and J. Guilpart, "Technical and economical model for the freezing cost comparison of immersion, cryomechanical and air blast freezing processes," Energy Convers. Manag., vol. 44, no. 4, pp. 559-571, 2003.

[9] R. J. Dossat., Principles of refrigeration, 4th ed., no. c. Englewood Cliffs, N.J. : Prentice Hall, 1997.

[10] P. Dempsey and P. Bansal, "The art of air blast freezing: Design and efficiency considerations," Appl. Therm. Eng., vol. 41, pp. 71-83, 2012.

[11] M. Justo, T. Andresen, F. Frydenlund, and K. N. Widell, "Improvements of air flow distribution in a freezing tunnel using Airpak," Ital. Oral Surg., vol. 1, no. 2211, pp. 1231-1238, 2011.

[12] H. T. Walnum, T. Andresen, and K. Widell, "Dynamic simulation of batch freezing tunnels for fish using Modelica," Procedia Food Sci., vol. 1, pp. 698-705, 2011. 